\title{
Community Health Implementation Model in Côte D'ivoire: Constraints and Limitations
}

\section{Adou Serge Judicaël ANOUA*}

Teacher-Researcher, Socio-Anthropologist, Alassane Ouattara University, Côte d'Ivoire

*Corresponding Author: Adou Serge Judicaël ANOUA, Teacher-Researcher, Socio-Anthropologist, Alassane Ouattara University, Côte d'Ivoire.

Received: May 28, 2019; Published: July 02, 2019

DOI: $10.31080 /$ ASMS.2019.03.0336

\begin{abstract}
Context/problematic: The implementation of community health in Côte d'Ivoire has taken form in a kind of collectivist management of health for more than two decades. This approach was concretized by the creation of community-based urban health units within the framework of the Abidjan health project in 1992. This institutional support had several missions, notably improving access to quality care at lower cost and diversifying primary care offers. In addition to these missions, community health education and information campaigns aiming at encourageing people to adopt more healthy behaviors. However, this way of operating the national health system in terms of health promotion remains insufficient in the face of persistent morbidities. Especially since we are seeing the progression of infectious, parasitic, chronic, degenerative, new diseases and reproductive health problems. In reality, health situation has difficulties to improve because of the lack of a citizen perspective. Thus, this research is intended to shed light on the constraints and limits of community health in Côte d'Ivoire.

Intervention: An exploratory visit of the structures in charge of health promotion and documentary funds permitted to impregnate the Ivorian experience and to elaborate the difficulties encountered then the limits in the state. Following this, the choice of the participatory approach was implemented in community health actions.

Results: Ultimately, community leaders and others are encouraged to be members of health or development committees and community councils. They participate in decision-making in terms of planning and implementation. This sign showing the interest of the community, as the partner in the initiated project, leads it to determine its own priorities according to the needs felt and to take measures accordingly.

Implications: Community health requires that community mobilization and organization favour articulation between the health promotion agent representing the formal care system, the community health worker as the liaison and the community. This could contribute to the emergence of citizen practices and collective responses to health problems.
\end{abstract}

Keywords: Community Health; Health; Côte d'Ivoire

\section{Introduction}

The implementation of community health in Côte d'Ivoire has been materialized by a form of collectivist management of health for more than two decades. However, this mode of operation remains insufficient. Especially infectious diseases, parasitic, chronic, degenerative, new and reproductive health problems appear still worrying today. Similarly, the lack of a citizen perspective is not made to reduce this burden of morbidity. Such a situation does not exclude effective constraints and limits in this community approach. This research aims at sheding light on the constraints and limits of community health in Côte d'Ivoire.

\section{Methods}

A visit to health promotion structures followed by semi-structured interviews with ten (10) institutional actors at the national 
and local levels and an observation of the documentary collections made it possible to learn from the Ivorian experience and to elaborate the difficulties encountered then the limits as they are.

\section{Results}

The Ivorian experience in community health

It is based on a systemic approach involving community-based health facilities and community health centers.

- Community-based urban health facilities represented institutional support. Their objective was the devolution of the management of the public health sector, the development of new administrative and financial management methods in the production of care and health planning, the establishment of community management, the regional information system and health plans, the implementation of a socio-economic and epidemiological study program and the monitoring of the implementation of public health programs.

- Community-based urban health centers proposed the implementation of prevention and care activities in health facilities integrated into the priority health program. They were based on active care and monitoring of chronic and parasitic diseases and reproductive health problems (HIV / AIDS, sexually transmitted diseases, tuberculosis, leprosy, diabetes, high blood pressure, malaria and kidney disease, pre and postnatal care, family planning, illegal abortion), care with active follow-up of vulnerable groups (women of reproductive age, young children and school children), promotional activities (water and sanitation), dialogue and participation at all levels of contact with the population (management committee, communication for behavior change), management of health centers (information system, financing, logistics) and training of health personnel, action research and evaluation of studies.

The limits of the Ivorian experience in community health.

They are of two kinds:

- $\quad$ From an epidemiological point of view, community health is medicalized since it is organized to cope with loads of infectious and parasitic morbidities, reproductive and maternal health problems as well as nutritional ones.
- From a structural point of view, community health is facing the problem of the availability of essential medicines in generic form, the organization of the empowerment and the participation of the communities, the organization of the pooling of the management of the disease, the progressive integration of vertical programs, the decentralization of health action and training, and the status of health promotion agents.

\section{Conclusion}

Community health requires that mobilization and community organization foster articulation between the health promotion agent representing the formal care system, the community health worker serving as the liaison and the community. This could contribute to the emergence of citizen practices and collective responses to health problems.

\section{Bibliography}

1. Christine Ortiz et Hortense Dogaud. Les Formations sanitaires à base communautaire à Abidjan : Un système naissant de pr paiement non mutualisé. Atelier Les mutuelles de santé en Afrique, Paris, CIDEF (1998).

2. République de Côte D'Ivoire.Politique nationale d'amélioration de la qualité des soins et des services de santé en Côte D’Ivoire. Abidjan, Ministère de la santé et de l'hygiène publique, PEPFAR, USAID (2016).

3. Service communication des Escom. Dossier santé communautaire/Les performances des centres de santé communautaires jamais révélées (2015).

\section{Volume 3 Issue 8 August 2019 (C) All rights are reserved by Adou Serge Judicaël ANOUA.}

